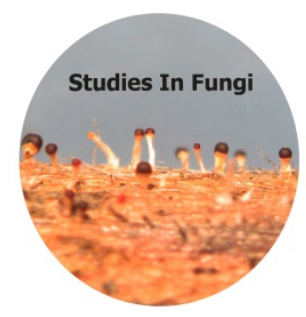

Studies in Fungi 4(1): 153-161 (2019) www.studiesinfungi.org ISSN 2465-4973

\title{
Article
}

Doi 10.5943/sif/4/1/18

\section{Cultivable yeasts associated with demosponges from Puerto Rico}

\section{Rosado-Rodríguez $\mathrm{G}^{1}$, Sánchez-Martínez $\mathrm{E}^{2}$, Maldonado-Ramírez $\mathrm{SL}^{2}$ and Otero $\mathbf{E}^{1}$}

${ }^{1}$ University of Puerto Rico at Mayagüez, Department of Marine Sciences, Call Box 9000, Mayagüez PR 00681

${ }^{2}$ University of Puerto Rico at Mayagüez, Department of Biology, Call Box 9000, Mayagüez PR 00681

Rosado-Rodríguez G, Sánchez-Martínez E, Maldonado-Ramírez SL, Otero E 2019 - Cultivable yeasts associated with demosponges from Puerto Rico. Studies in Fungi 4(1), 153-161, Doi 10.5943/sif/4/1/18

\begin{abstract}
Sponges are known for their symbiotic associations with bacteria and to a lesser extent with fungi. It has been argued that the association between fungi and sponges is not truly symbiotic, and fungal presence is incidental. Nevertheless, a vertically transmitted endosymbiotic yeast has been observed by transmission electron microscopy in sponges of the genus Chondrilla. Our work was focused on documenting the presence of yeasts associated with marine sponges from Puerto Rico. Sponge samples were taken from healthy mature colonies of Ircinia strobilina, Tedania ignis, and Chondrilla caribensis. A total of 36 yeast morphotypes were isolated and analysed by sequencing the nuclear ribosomal ITS region. Saccharomyces cerevisiae, was isolated from all the samples, comprising the first report of this yeast as a common inhabitant in marine sponges. Other yeasts isolated include the halophilic black yeast, Hortaea werneckii, and an unidentified species belongs to the Sporidiobolales (Basidiomycota). The high isolation frequency of $S$. cerevisiae from our sponge samples supports the possibility that Saccharomyces cerevisiae as an active member of the sponges’ microbial community.
\end{abstract}

Key words - fungi - Hortaea - marine sponges - Porifera - Rhodotorula - Saccharomyces cerevisiae

\section{Introduction}

Sponges are filter feeder organisms found in most marine environments. They are characterized by the absence of organized tissue layers and for being sessile organisms capable of filtering up to 20,000 times their volume in water in a single day (Rigby 1983). These organisms depend on a constant flow of water through their bodies to obtain food, oxygen and to remove wastes. It has been shown that marine sponges also form complex symbiotic associations with various groups of microorganisms, including bacteria, archaea, algae and fungi (Hentschel et al. 2002, Webster \& Taylor 2012). Their symbiotic products have pharmacological and biotechnological potential (Taylor et al. 2007, Thomas et al. 2010). The relationship between bacteria and sponges have been extensively studied. However, the relationship between marine sponges and fungi has received little attention and knowledge in this area is still limited.

The possibility of a symbiotic relationship between sponges and fungi is currently under debate, mainly because fungal diversity has shown not only to be highly similar to that from terrestrial environments, but also it is variable within sponges of the same species from same 
localities (Li \& Wang 2009). Although many fungal isolates have been identified as terrestrial, some isolates from sponges have shown unique metabolic capabilities that their terrestrial counterparts do not possess ( $\mathrm{Li} \&$ Wang 2009). There is only one example of an unknown endosymbiotic yeast from sponges of the genus Chondrilla, vertically transmitted through sponge eggs. (Maldonado et al. 2005). Evidence that further supports a symbiotic relationship between sponges and fungi is the presence of an intron in the mitochondrial DNA of a sponge with a putative fungal origin (Rot et al. 2006). The occurrence of this cross-kingdom horizontal gene transfer can only be explained by a long-term association of the sponge with the fungal donor. Furthermore, receptors for fungi occur in the sponge Suberites domuncula via D-glucan carbohydrates on fungal surfaces (Perović-Ottstadt et al. 2004), which can also be explained by a long-term association with fungi.

Fungi have been reported from marine sponges worldwide, and it has been proposed that sponges may be reservoirs for marine and terrestrial pathogens (Nguyen \& Thomas 2018). Some fungi reported from marine sponges are ecologically important, such as Aspergillus sydowii, responsible of the epizootic in gorgonians throughout the Caribbean (Alker et al. 2001). Although most fungi documented from marine sponges are culturable mycelial fungi, there are some reports of yeasts from various sponges worldwide (see Tables 1, 2). One of the most interesting reports from Gao et al. (2008), document the presence of various yeasts species belonging to the Malasseziales from Suberites zeteki and Mycale armata by culture independent techniques. To expand the knowledge in this area we documented the diversity of culturable yeasts from three demosponges from Puerto Rico: Tedania ignis, Chondrilla caribensis, and Ircinia strobilina.

\section{Materials \& Methods}

\section{Sample collection and processing}

Samples were collected from mangrove roots, coral reefs and seagrass beds from La Parguera Cays (southwestern Puerto Rico) on plastic Whirl-Pack ${ }^{\circledR}$ collection bags, placed in a cooler with ice, and transported to the laboratory for immediate processing. Water samples from the surrounding area were collected as controls. Samples were sealed underwater to avoid air contaminants. For the isolation of yeasts, two methods were applied: the traditional dilution-plate method and the highthroughput culture method (HTC) by dilution-to-extinction.

\section{Dilution plate method}

Sponge samples were surface washed with sterile natural seawater. For the preparation of the stock suspension, three portions of approximately $1 \mathrm{~cm}^{3}$ of the sponge mesohyl were homogenized in a blender with $10 \mathrm{~mL}$ of sterile natural seawater and serial dilutions from $10^{-1}$ to $10^{-4}$ of the resulting suspension were made. Each dilution was plated in triplicate on various culture media (marine agar, potato dextrose agar made with natural aged seawater, and yeast extract peptone dextrose agar made with natural aged seawater) and incubated at $22^{\circ} \mathrm{C} \pm 2{ }^{\circ} \mathrm{C}$ for up to 60 days to allow the isolation of slow growing colonies. All media were supplemented with thiamine and biotin, $8 \mathrm{mg} / \mathrm{mL}$ and $4 \mathrm{mg} / \mathrm{mL}$, respectively. A mixture of streptomycin and penicillin was added to the media to avoid bacterial growth. Individual colonies were then isolated for morphological characterization and molecular identification.

\section{High-throughput culture (HTC) method by dilution-to-extinction}

The method described by Collado et al. (2007) was applied with the following modifications: sponges were surface washed with natural sterile seawater. Subsequently, the sponge pinacoderm was removed from the samples to avoid the isolation of epibiotic fungi and three small portions of 1 $\mathrm{cm}^{3}$ of the sponge mesohyl were homogenized in $10 \mathrm{~mL}$ of sterile natural seawater. The resulting suspension was centrifuged at $2200 \mathrm{rpm}$ for 15 minutes to obtain a pellet. Each pellet was resuspended in $30 \mathrm{~mL}$ of $0.1 \%$ carboxymethyl cellulose to obtain the stock suspension and then a 1:80 dilution in sterile natural seawater was prepared. From the resulting dilution, $10 \mu \mathrm{L}$ aliquots 
were inoculated in each well of a 48-well tissue culture plate. Each well was previously prepared with $1 \mathrm{~mL}$ of yeast peptone dextrose agar made with aged natural sea water and supplemented with penicillin/streptomycin $10 \mathrm{mg} / \mathrm{ml}$. Excess water from the inoculated plates was dried in a laminar flow hood for 60 minutes and then sealed and incubated at $22^{\circ} \mathrm{C} \pm 2{ }^{\circ} \mathrm{C}$ ? and $80 \%$ relative humidity for up to 60 days. Selected morphotypes were isolated on Saboureaud Dextrose Agar (SDA) for characterization and molecular identification.

\section{DNA extraction and PCR amplification of the nuclear ribosomal internal transcribed spacer (ITS) region}

The rapid extraction protocol described by Cenis (1992) was followed with modifications. The modifications consisted of inoculation of the selected yeasts on $2 \mathrm{~mL}$ microcentrifuge tubes containing $1.5 \mathrm{~mL}$ of potato dextrose broth (PDB) prepared with aged natural seawater and incubated at $22^{\circ} \mathrm{C}$ for $72 \mathrm{~h}$ in a temperature-controlled shaker at $150 \mathrm{rpm}$. At the end of the incubation period, microtubes were centrifuged at 14,000 rpm for 5 minutes to obtain a pellet. The liquid media was decanted, and the pellet washed with $500 \mu \mathrm{L}$ of TE buffer and centrifuged as described before. The TE buffer was decanted and $300 \mu \mathrm{L}$ of extraction buffer $(200 \mathrm{mM}$ Tris-HCl pH 8.5, $250 \mathrm{mM} \mathrm{NaCl}, 25 \mathrm{mM}$ EDTA, 0.5\% SDS) was added. The procedure continued as described by Cenis (1992).

DNA fragments containing the ITS1, 5.8S, and ITS2 region were amplified and sequenced using the primer pair ITS1 (5'-TCCGTAGGTGAACCTGCGG-3') and ITS4 (5'TCCTCCGCTTATTGATATGC-3') developed by White et al. (1990) and the Promega Green Master Mix (\#M7122, Promega Corporation). The initial cycle of denaturation at $95^{\circ} \mathrm{C}$ for 3 minutes was followed by 30 cycles of denaturation at $95^{\circ} \mathrm{C}$ for 30 seconds, annealing at $54^{\circ} \mathrm{C}$ for 1 minute, and extension at $72^{\circ} \mathrm{C}$ for 2.5 minutes. A final extension step at $72^{\circ} \mathrm{C}$ for 10 minutes was done. PCR products of $\sim 450$ bp were verified by electrophoresis in a $1.5 \%$ agarose gel. Successful amplifications were sent for sequencing to the Molecular Cloning Laboratories (MCLAB, South San Francisco, CA).

\section{ITS sequence analysis}

DNA sequences were verified and edited in Sequencher 4.10 (CGene Codes Corporation). Blast searches of ITS sequences were performed in UNITE Database (Nilsson et al. 2018). Alignments with reference sequences from type specimens were done in MEGA version 7 (Kumar et al. 2016). Maximum likelihood phylogenies were reconstructed with the reference sequences in MEGA version 7.0 (Kumar et al. 2016). Nucleotide substitution model Kimura 2-parameter with a discrete Gamma distribution (K2+G) was selected using the Bayesian Information Criterion (BIC). Phylogenetic tree was edited in FigTree v.1.4.3 (Rambaut 2016). Phylogenetic tree and DNA sequence alignment are deposited in TreeBASE under Study ID number 24511.

\section{Results}

A total of 36 yeast morphotypes were isolated using both the traditional plate dilution technique and the HTC by dilution to extinction. Yeasts identified include the baker's yeast Saccharomyces cerevisiae, the black yeast Hortaea werneckii, and a yeast belonging to the Sporidiobolales, possibly within the genus Rhodotorula. The most frequently isolated yeast was $S$. cerevisiae, found in all the sponges from this study. Hortaea werneckii was represented by one isolate from Tedania ignis and another isolate from Chondrilla caribensis. The yeast belonging to the Sporidiobolales was represented by one isolate from Tedania ignis. The latter was characterized by soft-orange, mucilaginous colonies on SDA cultures after 7 days of incubation. Yeast cells were cylindrical with polar budding (Fig. 1A, 1B). No sexual reproduction was observed. The black yeast, $H$. werneckii, was characterized by smooth dark brown to black colonies after 7 days on SDA cultures, becoming fringed with olive-brown mycelia with age. This yeast was dematiaceous, 1-2 celled, often budding (Fig. 1C, 1D). Isolates of S. cerevisiae were characterized by smooth off- 
white to cream color after 7 days on SDA cultures, hyaline spherical budding cell and persistent asci with four globose ascospores (Fig. 1E, 1F).
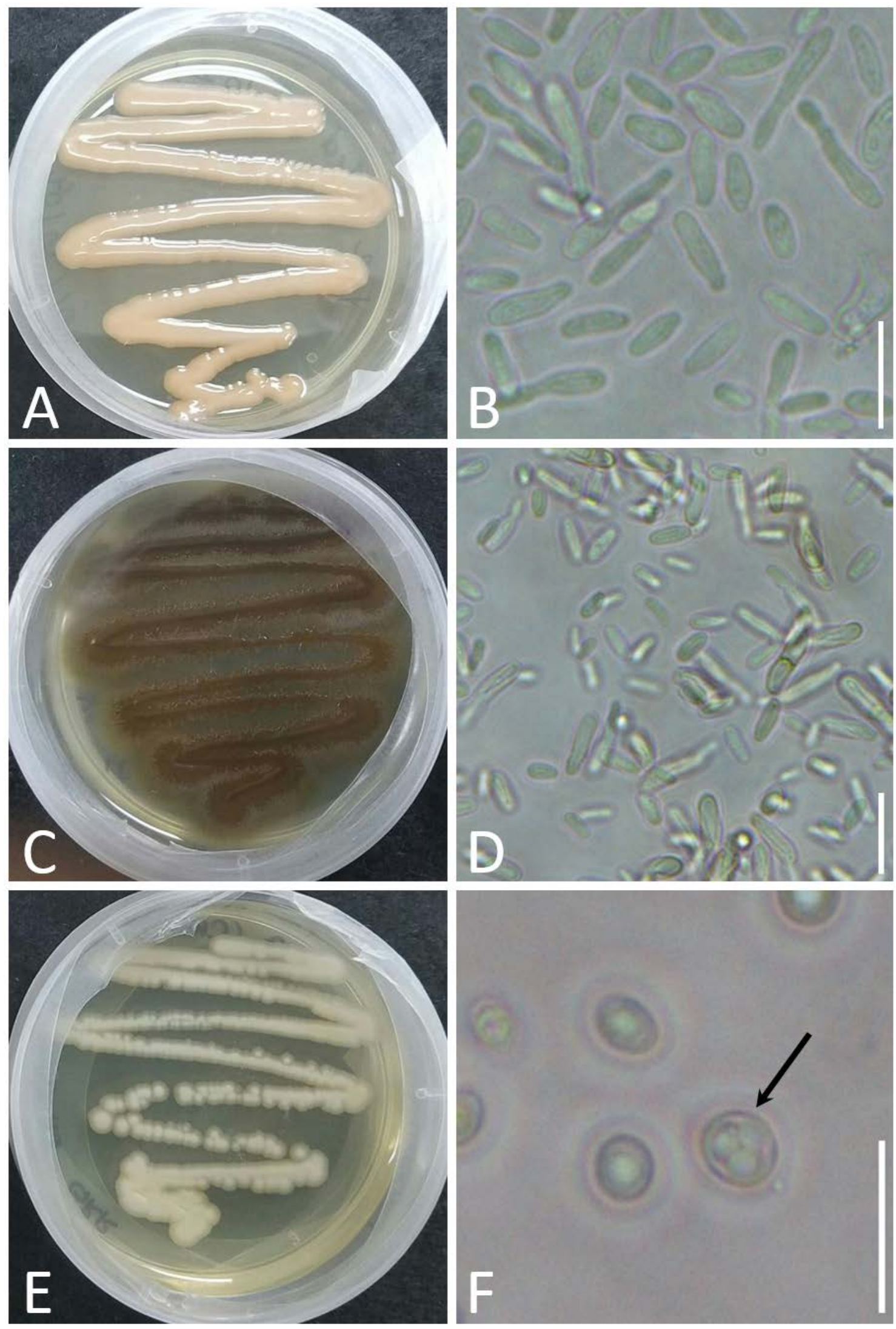

Fig. 1 - Macroscopic and microscopic view of isolated yeasts. A-B Rhodotorula sp., C-D Hortaea werneckii, and E-F Saccharomyces cerevisiae with ascospores within ascus (arrow). White bars represent $10 \mu \mathrm{m}$ scale. Phase-contrast microscopy (Nikon Eclipse -TS100 x100). 


\section{Phylogenetic analysis}

Maximum likelihood phylogeny of the nuclear ribosomal internal transcribed spacer (ITS) region of our isolates showed three distinct clades consisting of the orders Saccharomycetales, Capnodiales and Sporidiobolales (Fig. 2). Most of our sequences clustered within the Saccharomycetales, confirming the identification of our S. cerevisiae strains isolated from Tedania ignis and Chondrilla caribensis. The Capnodiales cluster contains isolate Y1B from Chondrilla caribensis, identified as $H$. werneckii. The clade of the Sporidiobolales contains 3 subclades corresponding to the three currently accepted genera within the order. Our isolate Y32 from Tedania ignis was nested within the Rhodotorula subclade. Nuclear ribosomal ITS sequences from our yeast isolates can be found in the NBCI GenBank database under accession numbers from MF118604 to MF118617.

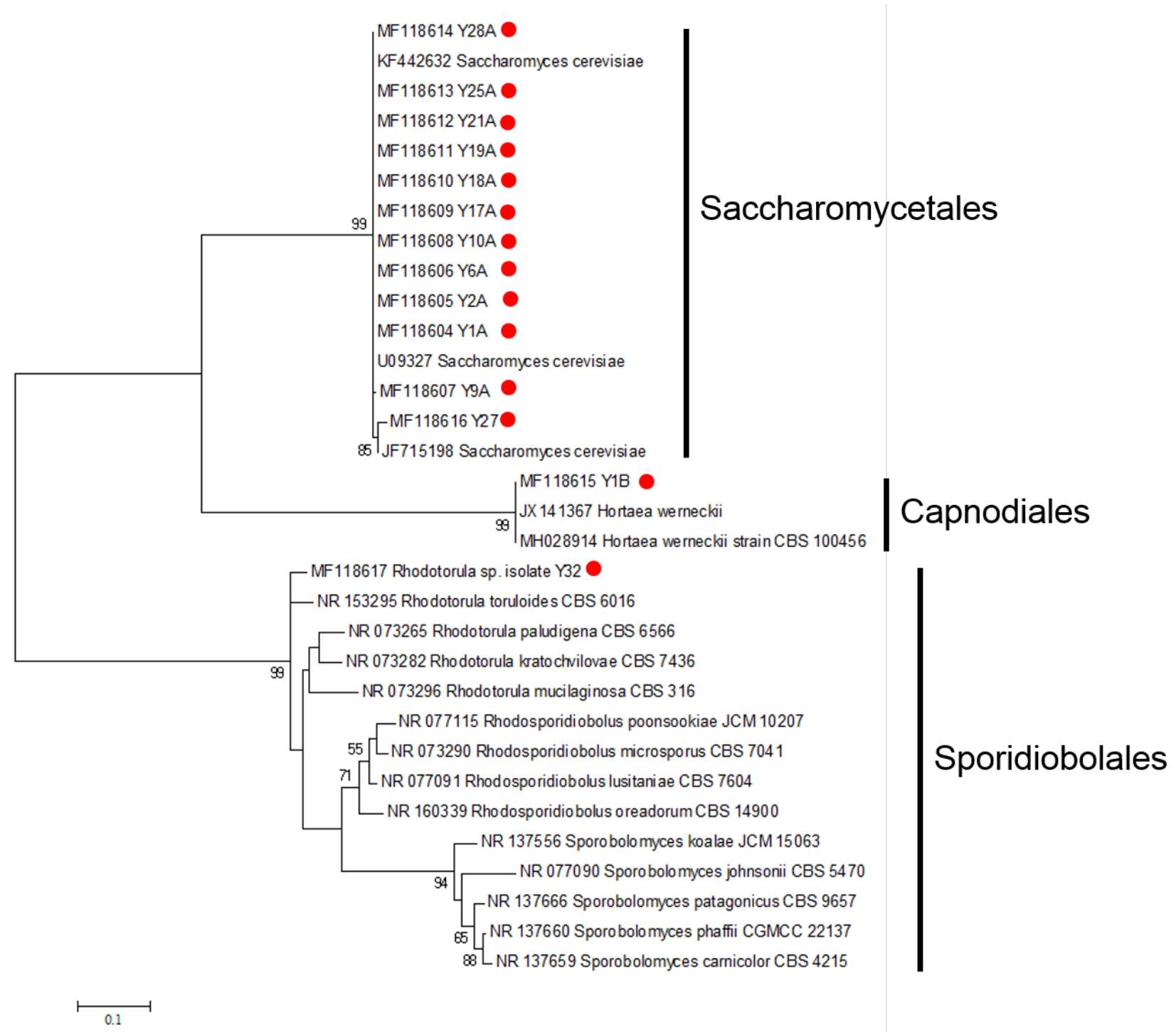

Fig. 2 - Maximum likelihood phylogram inferred from of the nuclear ribosomal internal transcribed spacer (ITS) region of yeasts isolated from marine sponges. Only bootstrap values above $50 \%$ are shown. Accession numbers are shown in the species labels. The scale represents the number of substitutions per site. Red circles represent sequences from this study.

\section{Discussion}

Yeast from two phyla and three orders were documented from our sponge samples. The baker's yeast, Saccharomyces cerevisiae, was recorded from all the sponges in this work, comprising the first report of this yeast as a common inhabitant of marine sponges. This yeast has 
been documented from a wide range of habitats, but no specific niche has been established. This led Goddard \& Greid (2015) to propose a new neutral ecology model for S. cerevisiae: the nomad model. They argued that $S$. cerevisiae is not adapted to a specific niche and that it has evolved the ability to inhabit and persist in many different environments. This yeast has been previously recorded from marine environments (Saravanakumar et al. 2012, Obara et al. 2015), so it is possible that the yeast enters the sponges through their water filtering activities. Given the high frequency of isolation from our samples, it seems that the yeast is a persisting member of the sponge's microbial community. In contrast, the low frequency of isolation for Hortaea werneckii and Rhodotorula from our sponges, although been previously isolated from sea water as well (Gao et al. 2008, Elsayed et al. 2016) do not seem to be as successful as S. cerevisiae as sponge inhabitants. Even though, $H$. werneckii has been previously reported from various marine sponges from Hawaii, China, and the Mediterranean (Table 1). Members of the genus Rhodotorula have been previously reported from sponges at the Brazilian Antarctic and South China Sea (Table 2). Our isolate (Rhodotorula sp. Y32) seems to be an undescribed species within the genus.

A summary of all the yeasts recorded from marine sponges worldwide up to the submission of this work for publication is presented in Tables 1, 2. A total of 13 ascomycetous and 17 basidiomycetous yeast species have been reported from marine sponges. Our yeast records comprise the first report for sponges from the Caribbean, and highlights Saccharomyces cerevisiae as a persistent inhabitant of marine sponges from Puerto Rico. Future work should focus on studying the presence of this yeast in sponges across a temporal scale to determine if it is a transient or a persistent member of their microbial community. Also, studies should expand to other taxa of sponges at different sites and depth. The metabolic capacities of these yeast should also be explored.

Table 1 Ascomycetous yeasts from marine sponges worldwide.

\begin{tabular}{|c|c|c|c|c|}
\hline Yeast & Sponge host & Source* & Location & Reference \\
\hline $\begin{array}{l}\text { Aureobasidium } \\
\text { pullulans }\end{array}$ & Suberites zeteki & ST, SW & Hawaii & Gao et al. 2008 \\
\hline Candida etchellsii & Haliclona simulans & ST & South China Sea & Liu et al. 2010 \\
\hline Candida glaebosa & Not specified & ST & South China Sea & Yu et al. 2013 \\
\hline \multirow[t]{3}{*}{ Candida parapsilosis } & Mycale armata & ST & Hawaii & Li \& Wang 2009 \\
\hline & Clathrina luteoculcitella & ST & South China Sea & Ding et al. 2011 \\
\hline & Not specified & ST & South China Sea & Yu et al. 2013 \\
\hline Candida sp. & Not specified & ST & South China Sea & Yu et al. 2013 \\
\hline Debaryomyces hansenii & Not specified & ST & Brazilian Antarctic & Duarte et al. 2013 \\
\hline \multirow[t]{6}{*}{ Hortaea werneckii } & Mycale armata & ST, SW & Hawaii & Gao et al. 2008 \\
\hline & Chondrilla caribensis & ST & Puerto Rico & This study \\
\hline & Gelliodes carnosa & ST & South China Sea & Liu et al. 2010 \\
\hline & Aplysina aerophoba & ST & Mediterranean & Brauers et al. 2001 \\
\hline & Haliclona simulans & ST & South China Sea & Liu et al. 2010 \\
\hline & Tedania ignis & ST & Puerto Rico & This study \\
\hline Lacazia loboi & Mycale armata & ST & Hawaii & Li \& Wang 2009 \\
\hline \multirow{5}{*}{$\begin{array}{l}\text { Metschnikowia } \\
\text { australis }\end{array}$} & Dendrilla sp. & ST & Antarctic & Vaca et al. 2013 \\
\hline & Hymeniacidon sp. & ST & Antarctic & Vaca et al. 2013 \\
\hline & Poecilosclerida 1 & ST & Antarctic & Vaca et al. 2013 \\
\hline & Poecilosclerida 2 & ST & Antarctic & Vaca et al. 2013 \\
\hline & Tedania sp. & ST & Antarctic & Vaca et al. 2013 \\
\hline $\begin{array}{l}\text { Metschnikowia } \\
\text { bicuspidata }\end{array}$ & Haliclona simulans & ST & West Coast Ireland & Baker et al. 2009 \\
\hline \multirow[t]{2}{*}{ Pichia membranifaciens } & Halichondria okadai & ST & Japan & $\begin{array}{l}\text { Sugiyama et al. } \\
2009\end{array}$ \\
\hline & Petrosia sp. & ST & South Korea & Elbandy et al. 2008 \\
\hline
\end{tabular}


Table 1 Continued.

\begin{tabular}{lllll}
\hline Yeast & Sponge host & Source* & Location & Reference \\
\hline $\begin{array}{l}\text { Saccharomyces } \\
\text { cerevisiae }\end{array}$ & Ircinia strobilina & ST & Puerto Rico & This study \\
& $\begin{array}{l}\text { Chondrilla caribensis } \\
\text { Tedania ignis }\end{array}$ & ST & Puerto Rico & This study \\
Yarrowia lipolytica & ST & Puerto Rico & This study \\
& $\begin{array}{l}\text { Cinachyrella } \\
\text { australiensis }\end{array}$ & ST & South China Sea & Yu et al. 2013 \\
\hline *ST= sponge tissue; SW= sea water & & & \\
\end{tabular}

*ST= sponge tissue; $\mathrm{SW}=$ sea water

Table 2 Basidiomycetous yeast reported from marine sponges worldwide.

\begin{tabular}{|c|c|c|c|c|}
\hline Yeast & Sponge host & Source* & Location & Reference \\
\hline Bullera pseudoalba & Not specified & ST & Brazilian Antarctic & Duarte et al. 2013 \\
\hline Cryptococcus foliicola & Gelliodes carnosa & ST & South China Sea & Liu et al. 2010 \\
\hline Cryptococcus laurentii & Not specified & ST & Brazilian Antarctic & Duarte et al. 2013 \\
\hline \multirow[t]{2}{*}{$\begin{array}{l}\text { Cystofilobasidium } \\
\text { infirmominiatum }\end{array}$} & Tedania sp. & ST & Antarctic & Vaca et al. 2013 \\
\hline & Hymeniacidon sp. & ST & Antarctic & Vaca et al. 2013 \\
\hline Kondoa malvinella & Haliclona simulans & ST & South China Sea & Liu et al. 2010 \\
\hline $\begin{array}{l}\text { Leucosporidiella } \\
\text { creatinivora }\end{array}$ & Tedania sp. & ST & Antarctic & Vaca et al. 2013 \\
\hline $\begin{array}{l}\text { Leucosporidium } \\
\text { escuderoi }\end{array}$ & Hymeniacidon sp. & $\mathrm{ST}$ & Antarctic & Vaca et al. 2013 \\
\hline Malassezia globose & Mycale armata & ST, SW & Hawaii & Gao et al. 2008 \\
\hline \multirow[t]{2}{*}{ Malassezia restricta } & Mycale armata & ST & Hawaii & Gao et al. 2008 \\
\hline & Suberites zeteki & ST & Hawaii & Gao et al. 2008 \\
\hline Malassezia sympodialis & Mycale armata & ST, SW & Hawaii & Gao et al. 2008 \\
\hline Rhodotorula sp. & Tedania ignis & ST & Puerto Rico & This study \\
\hline $\begin{array}{l}\text { Rhodotorula } \\
\text { mucilaginosa }\end{array}$ & Not specified & ST & Brazilian Antarctic & Duarte et al. 2013 \\
\hline Rhodotorula pinicola & Hymeniacidon sp. & ST & Antarctic & Vaca et al. 2013 \\
\hline $\begin{array}{l}\text { Sporidiobolus } \\
\text { pararoseus }\end{array}$ & Geodia neptuni & ST & South China Sea & Yu et al. 2013 \\
\hline \multirow{2}{*}{$\begin{array}{l}\text { Sterigmatomyces } \\
\text { halophillus }\end{array}$} & Gelliodes carnosa & ST & South China Sea & Liu et al. 2010 \\
\hline & Haliclona simulans & ST & South China Sea & Liu et al. 2010 \\
\hline $\begin{array}{l}\text { Trichosporon } \\
\text { montevideense }\end{array}$ & Not specified & ST & South China Sea & Yu et al. 2013 \\
\hline Trichosporon sp. & Psammocinia sp. & ST & Mediterranean & Paz et al. 2010 \\
\hline
\end{tabular}

*ST= sponge tissue; $\mathrm{SW}=$ sea water

\section{Acknowledgements} NCE).

This work was partially supported by the Howard Hughes Medical Institute (HHMI 2012-

\section{References}

Alker AP, Smith GW, Kim K. 2001 - Characterization of Aspergillus sydowii (Thom et Church), a fungal pathogen of Caribbean sea fan corals. Hydrobiologia 460, 105-111.

Baker PW, Kennedy J, Dobson ADW, Marchesi JR. 2009 - Phylogenetic diversity and antimicrobial activities of fungi associated with Haliclona simulans isolated from Irish coastal waters. Marine Biotechnology 11, 540-547. 
Brauers G, Ebel R, Edrada RA, Wray V et al. 2001 - Hortein, a new natural product from the fungus Hortaea werneckii associated with the sponge Aplysina aerophoba. Journal of Natural Products 64, 651-652.

Cenis JL. 1992 - Rapid extraction of fungal DNA for PCR amplification. Nucleic Acids Research 20(9), 2380.

Collado J, Plastas G, Paulus B, Bills GF. 2007 - High-throughput culturing of fungi from plant litter by a dilution-to-extinction technique. FEMS Microbiol Ecology 60, 521-533.

Ding B, Yin Y, Zhang F, Li Z. 2011 - Recovery and phylogenetic diversity of culturable fungi associated with marine sponges Clathrina luteoculcitella and Holoxea sp. in the South China Sea. Marine Biotechnology 13(4), 713-721.

Duarte AWF, Dayo-Owoyemi I, Nobre FS, Pagnocca FC et al. 2013 - Taxonomic assessment and enzymes production by yeasts isolated from marine and terrestrial Antarctic samples. Extremophiles 17(6), 1023-1035.

Elbandy M, Shinde PB, Dang HT, Hong J et al. 2008 - Furan metabolites from the sponge-derived yeast Pichia membranifaciens. Journal of Natural Products 71, 869-872.

Elsayed A, Mowafy AM, Soliman HM, Gebreil A, Magdy NI. 2016 - Characterization of new strains of Hortaea werneckii isolated from salt marshes of Egypt. Egyptian Journal of Basic and Applied Sciences 3(4), 350-356.

Gao Z, Li B, Zheng C, Wang G. 2008 - Molecular detection of fungal communities in the Hawaiian marine sponges Suberites zeteki and Mycale armata. Applied and Environmental Microbiology 74(19), 6091-6101.

Goddard MR, Greig D. 2015 - Saccharomyces cerevisiae, a nomadic yeast with no niche? FEMS Yeast Research 15(3), 1-6.

Hentschel U, Hopke J, Horn M, Friedrich AB et al. 2002 - Molecular evidence for a uniform microbial community in sponges from different oceans. Applied Environmental Microbiology 68(9), 4431-4440.

Kumar S, Stecher G, Tamura K. 2016 - MEGA7: Molecular Evolutionary Genetics Analysis version 7.0 for bigger datasets. Molecular Biology and Evolution 33, 1870-1874.

Li Q, Wang G. 2009 - Diversity of fungal isolates from three Hawaiian marine sponges. Microbiological Research 164, 233-241.

Liu WC, Li CQ, Yang JL, Cheng KD. 2010 - Phylogenetic diversity of culturable fungi associated with two marine sponges: Haliclona simulans and Gelliodes carnosa, collected from the Hainan Island coastal waters of the South China Sea. Fungal Diversity 42, 1-15.

Maldonado M, Cortadellas N, Trillas, MI, Rützler K. 2005 - Endosymbiotic yeast maternally transmitted in a marine sponge. The Biological Bulletin 209, 94-106.

Nguyen M, Thomas T. 2018 - Diversity, host-specificity and stability of sponge-associated fungal communities of co-occurring sponges. PeerJ 6:e4965; DOI 10.7717/peerj.4965.

Nilsson RH, Larsson K-H, Taylor AFS, Bengtsson-Palme J et al. 2018 - The UNITE database for molecular identification of fungi: handling dark taxa and parallel taxonomic classifications. Nucleic Acids Research 47(D1), D259-D264.

Obara N, Oki N, Okai M, Ishida M, Urano N. 2015 - Development of a simple technique for yeast Saccharomyces cerevisiae with high fermentative activities from coastal waters. Studies in Science and Technology 4(1), 71-76.

Paz Z, Komon-Zelazowska M, Druzhinina IS, Aveskamp MM et al. 2010 - Diversity and potential antifungal properties of fungi associated with a Mediterranean sponge. Fungal Diversity 42, $17-26$.

Perović-Ottstadt S, Adell T, Proksch P, Wiens M et al. 2004 - A $(1 \rightarrow 3)-\beta$-D-glucan recognition protein from the sponge Suberites domuncula. European Journal of Biochemistry 271, 1924 1937.

Rambaut A. 2016 - FigTree: Tree figure drawing tool, version 1.4.3. Institute of Evolutionary Biology, University of Edinburgh. Available at http://tree.bio.ed.ac.uk/software/figtree. 
Rigby JK. 1983 - Introduction to the Porifera. In: Rigby, J.K. and Steam, C.W. Ed. Sponges and Spongiomorphs. Notes for a Short Course, Vol. 7. Stud. Geol. Univ., Tennessee, pp. 1-11.

Rot C, Goldfarb I, Ilan M, Huchon D. 2006 - Putative cross-kingdom horizontal gene transfer in sponge (Porifera) mitochondria. BMC Evolutionary Biology 6:71. Available at http://www.biomedcentral.com/1471-2148/6/71.

Saravanakumar K, Senthilraja P, Kathiresan K. 2012 - Bioetanol production by mangrove-derived marine yeast, Saccharomyces cerevisiae. Journal of King Saud University - Science 25(2), 121-127.

Sugiyama Y, Ito Y, Suzuki M, Hirota A. 2009 - Indole derivatives from a marine sponge-derived yeast as DPPH radical scavengers. Journal of Natural Products 72(11), 2069-2071.

Taylor MW, Radax R, Steger D, Wagner M. 2007 - Sponge-associated microorganisms: evolution, ecology, and biotechnological potential. Microbiology and Molecular Biology Reviews. 71(2), 295-347.

Thomas TRA, Kavlekar DP, LokaBharathi PA. 2010 - Marine drugs from sponge-microbe association - A review. Marine Drugs 8, 1417-1468.

Vaca I, Faúndez C, Maza F, Paillavil B et al. 2013 - Cultivable psychrotolerant yeasts associated with Antarctic marine sponges. World Journal of Microbiology and Biotechnology 29, 183189.

Webster NS, Taylor MW. 2012 - Marine sponges and their microbial symbionts: love and other relationships. Environmental Microbiology 14(2), 335-346.

White TJ, Bruns T, Lee S, Taylor J. 1990 - Amplification and direct sequencing of fungal ribosomal RNA genes for phylogenetics. In: PCR Protocols: a guide to methods and applications. (Innis MA, Gelfand DH, Sninsky JJ, White TJ, eds). Academic Press, New York, USA, pp. 315-322.

Yu Z, Zhang B, Sun W, Zhang F, Li Z. 2013 - Phylogenetically diverse endozoic fungi in the South China Sea sponges and their potential in synthesizing bioactive natural products suggested by PKS gene and cytotoxic activity analysis. Fungal Diversity 58, 127-141. 